\title{
Ordenação de alternativas de biomassa utilizando o apoio multicritério à decisão
}

\author{
Carlos Francisco Simões Gomes ${ }^{\mathrm{a} *}$, Ana Claudia Coenca Maia ${ }^{\mathrm{b}}$ \\ a*carlos.francisco@pq.cnpq.br, UFF, Brasil \\ bcoenca@gmail.com, lbmec, Brasil
}

\begin{abstract}
Resumo
Este artigo refere-se ao estudo de ordenação de uma fonte de energia limpa e renovável denominada biomassa. Nos dias atuais observa-se uma demanda mundial crescente por energias ditas renováveis. A produção de energia elétrica a partir da biomassa é muito defendida como uma importante contribuição para o desenvolvimento de muitos países. 0 objetivo deste artigo é mostrar o potencial dessa fonte de energia. A biomassa, como uma das alternativas limpas e seguras para solucionar um possível racionamento que o Brasil poderá enfrentar nos próximos anos devido ao descompasso do crescimento da demanda por energia e o crescimento da oferta de energia elétrica em nosso país. Palavras-chave
\end{abstract}

Biomassa. Energia. Multicritério.

\section{Introdução}

Observa-se atualmente uma preocupação mundial na produção e consumo de formas de energia mais limpas. Para que essas formas de energia, ditas renováveis, tornem-se viáveis, é necessário que elas e o seu processo de produção sejam sustentáveis do ponto de vista socioeconômico e competitivas no mercado globalizado (CARMO; BARROS NETO; DUTRA, 2011).

Os recursos renováveis representam cerca de 20\% do suprimento total de energia do mundo, sendo $14 \%$ proveniente de biomassa e $6 \%$ de fonte hídrica. No Brasil, a proporção da energia total consumida é em cerca de 35\% de origem hídrica e em 25\% de origem em biomassa, significando que os recursos renováveis suprem aproximadamente dois terços da demanda de energia do país (VALOR..., 2008). Entre os principais tipos de biomassa estão a cana-de-açúcar para a produção de etanol e óleos vegetais para a produção de biodiesel. Estas matérias-primas possuem "boa" disponibilidade na natureza, e o seu uso não agride o meio ambiente, fazem parte de um processo produtivo sustentável, atributo de grande importância no mundo contemporâneo. 0 aquecimento global colocou em discussão a responsabilidade social das empresas/países na adoção de matérias-primas geradoras de energia limpa. 0 uso de energia limpa pode ser a solução frente à escassez de petróleo: são originadas de ciclos naturais e praticamente inesgotáveis; não provocam alterações no balanço térmico do planeta; e são lucrativas, pois dão às empresas a possibilidade de negociar créditos no mercado de carbono. 0 segmento, formado no âmbito do Mecanismo de Desenvolvimento Limpo (MDL), faz parte da implementação do Protocolo de Kyoto e está em vigor desde fevereiro de 2004, porém este documento internacional que visa reduzir ou limitar as emissões de gases causadores do efeito estufa até 2012 é rejeitado pelos EUA (ALVES, 2007).

As empresas que utilizam tecnologias limpas no mercado brasileiro podem ainda contar com o Programa de Desenvolvimento Limpo do Banco Nacional de Desenvolvimento Econômico e Social (BNDES). Lançado em julho de 2007, esse financiamento estimula iniciativas empresariais de preservação do meio ambiente em detrimento de atividades poluentes. 0 programa, instalado pelo BNDESPAR ou BNDESPar, 
uma holding brasileira de propriedade do BNDES criada para administrar as participações do banco em diversas empresas, prevê a formação de fundos mútuos fechados de investimento. A finalidade dessa modalidade financeira é apoiar projetos que atendam a Redução Certificada de Emissões ou créditos de carbono (RCE). A expectativa do banco de fomento é aumentar a atratividade econômica de operações como geração de energia elétrica e de projetos com foco na eficiência energética.

No estado de São Paulo existem 146 usinas de cogeração em operação, com potência instalada total de $1.700 \mathrm{MW}$, o que corresponde a 70\% da cogeração no Brasil. Parte dessa energia é utilizada para atender a necessidade das usinas e o resto é vendido no mercado (GOES, 2008). Bagaço cogeração descreve o uso de resíduos com muita fibra como o bagaço de cana-de-açúcar para gerar energia elétrica de alta eficiência nas fábricas de açúcar. Existe abundante oportunidade para uma ampla utilização do bagaço de cana como base na cogeração nos países produtores de cana e de contribuir substancialmente para a elevada eficiência da produção energética. No entanto, este potencial permanece largamente inexplorado. A Figura 1 mostra um diagrama dos processos de conversão da matéria-prima em biomassa.

Este artigo tem como propósito analisar e comparar alguns tipos de energia produzidos por biomassa. Analisar-se-á a biomassa oriunda do bagaço de cana, licor negro, resíduos de madeira, biogás e casca de arroz Este estudo teve origem em Maia (2008), com dados de 2007. Este estudo usa dados atualizados em 2011.

\section{Setor energético}

No Brasil, a oferta de energia é cerca de 100 mil megawatts de capacidade instalada e a demanda é de 53,5 mil MW. De 2005 para 2007 ocorreu um aumento total de 7,9\% na demanda. 0 consumo de eletricidade no Brasil deve se aproximar de 1.200 terawatts-hora (TWh) em 2030. lsso deve ocorrer devido à previsão de um crescimento anual médio de $4 \%$ no uso de eletricidade. 0 aumento do consumo é consequência do crescimento da população, que deve passar dos atuais 188 milhões de habitantes para 243 milhões (em 2030), e da universalização do serviço. Outro motivo é a melhora da renda da população. A expectativa do governo era que a conclusão do Programa Luz para Todos, em 2008, permitisse a oferta de eletricidade em todas as residências da zona rural do país (AGÊNCIA..., 2011). A Tabela 1 apresenta a projeção de domicílios no Brasil.

De acordo com o site http://200.198.213.102/ luzparatodos/downloads/Informativo\%2015.pdf, até dezembro de 2008, 9,3 milhões de pessoas foram beneficiadas com o programa. A busca de um melhor padrão de vida, ocasionado pela elevação de renda, fez

Energético

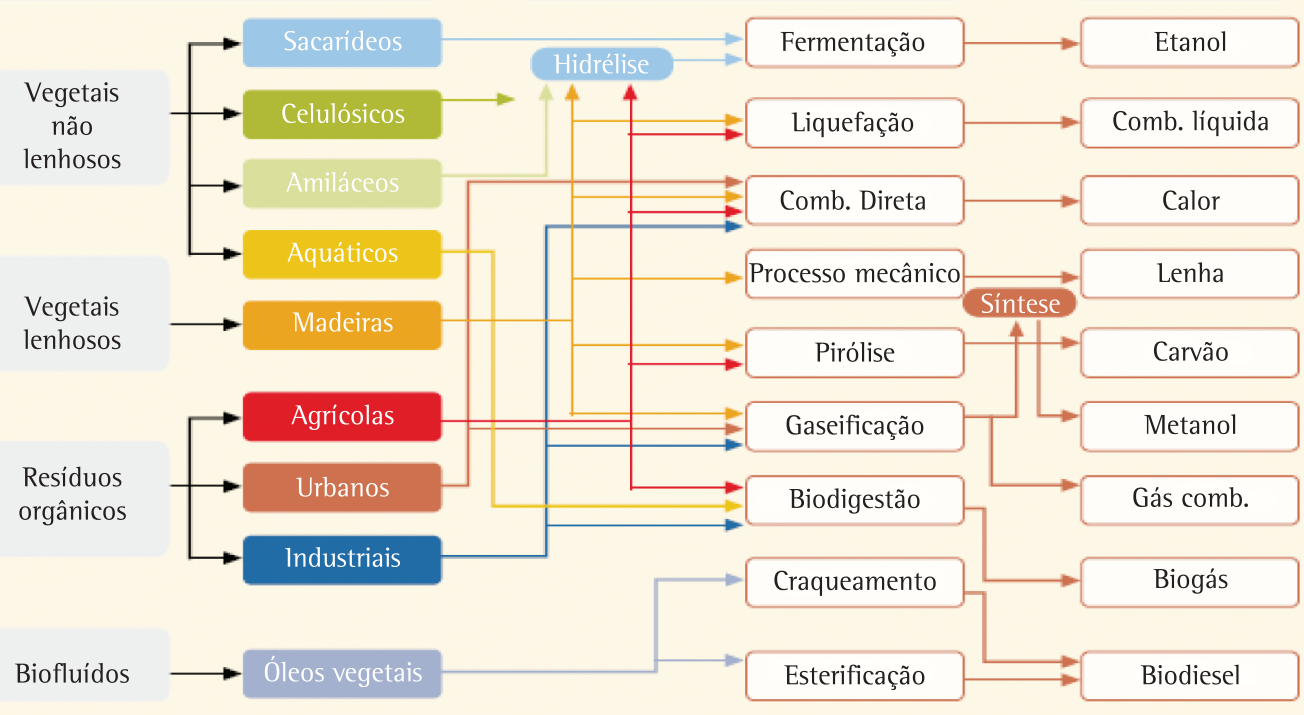

Figura 1. Processos de conversão energética da biomassa (site ANEEL). 
Tabela 1. Brasil e regiões 2010-2019 - projeção de domicílios.

\begin{tabular}{|c|c|c|c|c|c|c|}
\hline Ano & Norte & Nordeste & Sudeste & Sul & Centro-oeste & Brasil \\
\hline 2010 & 4.259 & 15.295 & 27.152 & 9.591 & 4.547 & 60.884 \\
\hline 2014 & 4.725 & 16.660 & 29.692 & 10.533 & 5.051 & 66.662 \\
\hline 2019 & 5.305 & 18.334 & 21.917 & 11.723 & 5.663 & 73.992 \\
\hline \multicolumn{7}{|c|}{ Variação média (\% ano) } \\
\hline 2010-14 & 2,6 & 2,2 & 2,3 & 2,4 & 2,7 & 2,3 \\
\hline 2015-19 & 2,3 & 2,0 & 2,1 & 2,2 & 2,3 & 2,2 \\
\hline 2010-19 & 2,5 & 2,1 & 2,2 & 2,3 & 2,5 & 2,2 \\
\hline \multicolumn{7}{|c|}{ Estrutura de participação (\%) } \\
\hline 2010 & 7,0 & 25,2 & 44,7 & 15,8 & 7,4 & 100 \\
\hline 2014 & 7,1 & 25,0 & 44,6 & 15,8 & 7,6 & 100 \\
\hline 2019 & 7,2 & 24,9 & 44,5 & 15,8 & 7,6 & 100 \\
\hline
\end{tabular}

Fonte: http://www.epe.gov.br/PDEE/20101129_1.pdf.

com que os brasileiros comprassem uma quantidade maior de eletrodomésticos para sua residência, isso pode ser comprovado pelo aumento de venda desses produtos nas lojas. Os níveis de consumo de eletricidade per capita devem continuar crescendo em ritmo semelhante ao registrado nas últimas décadas.

Entretanto a crise desencadeada no último trimestre de 2008 gerou uma diminuição no ritmo de crescimento da demanda. Segundo a Revista Exame de abril de 2008 (GASPAR, 2008), nas residências o consumo por pessoa entre 1970 e 2005 subiu de 90 quilowatts-hora (kWh) para $452 \mathrm{kWh}$ por ano. A previsão é que, até 2030, o consumo per capita atinja $1.200 \mathrm{kWh}$. Se as previsões estiverem corretas, os investimentos em novas usinas serão indispensáveis para evitar o risco de um apagão energético no futuro. A estimativa é que até 2018 serão investidos $\mathrm{R} \$ 134$ bilhões em novas usinas. A preocupação da sociedade com as questões ambientais fará com que as usinas energéticas fiquem cada vez mais eficientes. 0 governo considera a implantação de leilões de eficiência energética nos quais projetos de conservação de energia concorreriam com novas usinas. As perspectivas são que esse tipo de medida permitirá uma economia da ordem de 10\% no consumo de eletricidade previsto para 2030 (EMPRESA..., 2001; WORLD..., 2009). 0 ano de 2007 foi marcado pelo bom desempenho da atividade econômica, com uma taxa de crescimento do PIB superior a 5\%, impulsionada pelo nível mais baixo das taxas de juros reais e pelo acelerado crescimento da oferta de crédito, que evoluiu 27,3\% no ano, de acordo com indicadores do Banco Central. 0 fluxo de entrada de dólares manteve-se abundante, levando a uma valorização de 17\% do real em comparação ao dólar. A recuperação mundial das cotações dos alimentos pressionou os índices de preços no final de 2007, levando o IPCA a encerrar 2007 muito próximo da meta de 4,5\% e o Banco Central a interromper o ciclo de flexibilização da política monetária, após reduzir a taxa Selic de
$13,25 \%$ para $11,25 \%$. Para 2008 , as perspectivas para a economia brasileira seguiam positivas, ainda que cercadas de maior cautela por conta das incertezas que rondam o cenário internacional. Essas incertezas se confirmaram com a crise internacional no final de 2008. Nesse cenário, o consumo de energia no país cresceu 4,8\% no ano, segundo balanço divulgado pelo Operador Nacional do Sistema Elétrico (ONS) no final de dezembro de 2007, percentual abaixo da variação do PIB, mas superior aos 3,5\% registrados no ano anterior. Esse descolamento, segundo a entidade, pode indicar uma maior participação de segmentos não intensivos em energia na economia brasileira e o aumento da autoprodução de energia por grandes consumidores. Esse descompasso entre a oferta e a demanda por energia elétrica em nosso país pode ser observado na Figura 2.

Salienta-se que o Brasil possui a quarta maior população mundial, mas a oferta energética em 2010 foi de apenas 1,419 tep (tonelada equivalente de petróleo por pessoa/ano), enquanto a média mundial é 1,7 tep e a média dos países ricos, 4,7 tep (EMPRESA..., 2001). 0 balanço do ONS aponta que a carga de energia no país - que inclui consumo e perdas de eletricidade no sistema - atingiu 49.734 MW médios em 2007, em comparação a 47.473 MW médios em 2006. A maior alta de consumo (5\%) ocorreu nas regiões Sudeste e Centro-oeste, subsistema que representa $62 \%$ da carga de energia do país. No Nordeste, o crescimento foi de 4,8\%, impulsionado pelo desenvolvimento econômico regional provocado pelos programas sociais do governo. No Sul, o crescimento na carga de energia foi de $4 \%$, com forte influência da retomada da produção agrícola. Já no Norte, o aumento foi de 3,7\%. No decorrer de 2007, a agenda do setor elétrico voltou a incluir o debate sobre os riscos de desabastecimento de energia. Essa preocupação decorre de atrasos em licenciamentos e obras de centrais hidrelétricas, problemas de fornecimento de gás natural da Bolívia, 
que abastece centrais termelétricas, e redução dos níveis de reservatórios hídricos, em decorrência de menores volumes de chuvas no período do verão (ANEEL). A geração de energia elétrica em todo país, segundo o ONS, atingiu 116.581 MW em 2011. Nos próximos anos deverá ocorrer uma diversificação na matriz energética do Brasil, segundo estudos da EPE, que apontam que a participação das hidrelétricas no país na produção de eletricidade deve cair dos atuais $74,9 \%$ (em novembro de 2011) para 65\% até 2016. Com isso, a geração térmica, que inclui fontes como gás natural, carvão mineral, óleo combustivel e biomassa, passará dos atuais $22,18 \%$ para quase $30 \%$ no período em questão. Indica o fim da hidroeletricidade abundante e próxima dos grandes centros de consumo. Simultaneamente, deve garantir maior segurança de abastecimento. Uma vez que reduzirá a dependência de uma única fonte (Figura 2). Até 2016, vislumbra-se como cenário que o parque gerador brasileiro saia dos atuais $116,5 \mathrm{GW}$ instalados para $150 \mathrm{GW}$. As Tabelas 2 e 3 apresentam o consumo por fonte e a capacidade instalada.

\subsection{Biomassa}

Biomassa é ainda um termo pouco conhecido fora dos campos da energia e da ecologia mas já faz parte do cotidiano brasileiro. Fonte de energia não poluente, a biomassa nada mais é do que a matéria orgânica de origem animal ou vegetal que pode ser utilizada na produção de energia. A participação da biomassa na matriz energética brasileira é de 20\% da energia consumida no país (BIOWARE, 2009; EMPRESA..., 2001).

A biomassa é uma forma indireta de aproveitamento da energia solar absorvida pelas plantas (vida vegetal), já que resulta da conversão da luz do sol em energia química. Estima-se que existam 2 trilhões de toneladas de biomassa no globo terrestre, ou cerca de 400 toneladas por pessoa. Em termos energéticos, corresponde a oito vezes o consumo anual mundial de energia primária (produtos energéticos providos pela natureza na sua forma direta, como o petróleo, gás natural, carvão mineral, minério de urânio, lenha e outros) (BIOWARE, 2009).

A Empresa de Pesquisa Energética (EPE) prevê que a cana-de-açúcar e seus derivados se tornem a segunda fonte de energia mais importante no Brasil. Com 19\% de participação, ficarão atrás apenas do petróleo e derivados. No setor elétrico, o insumo agrícola deve gerar 6,3 mil MW. Por isso, da projeção de investimentos até 2030, US\$ 32 bilhões estão planejados para a geração a partir do insumo agrícola (EMPRESA..., 2001). Em condições favoráveis, a biomassa pode contribuir de maneira significante para a produção de energia elétrica. Segundo estimativas do pesquisador Hall, a recuperação de um terço dos resíduos disponíveis viabilizaria o atendimento de 10\%

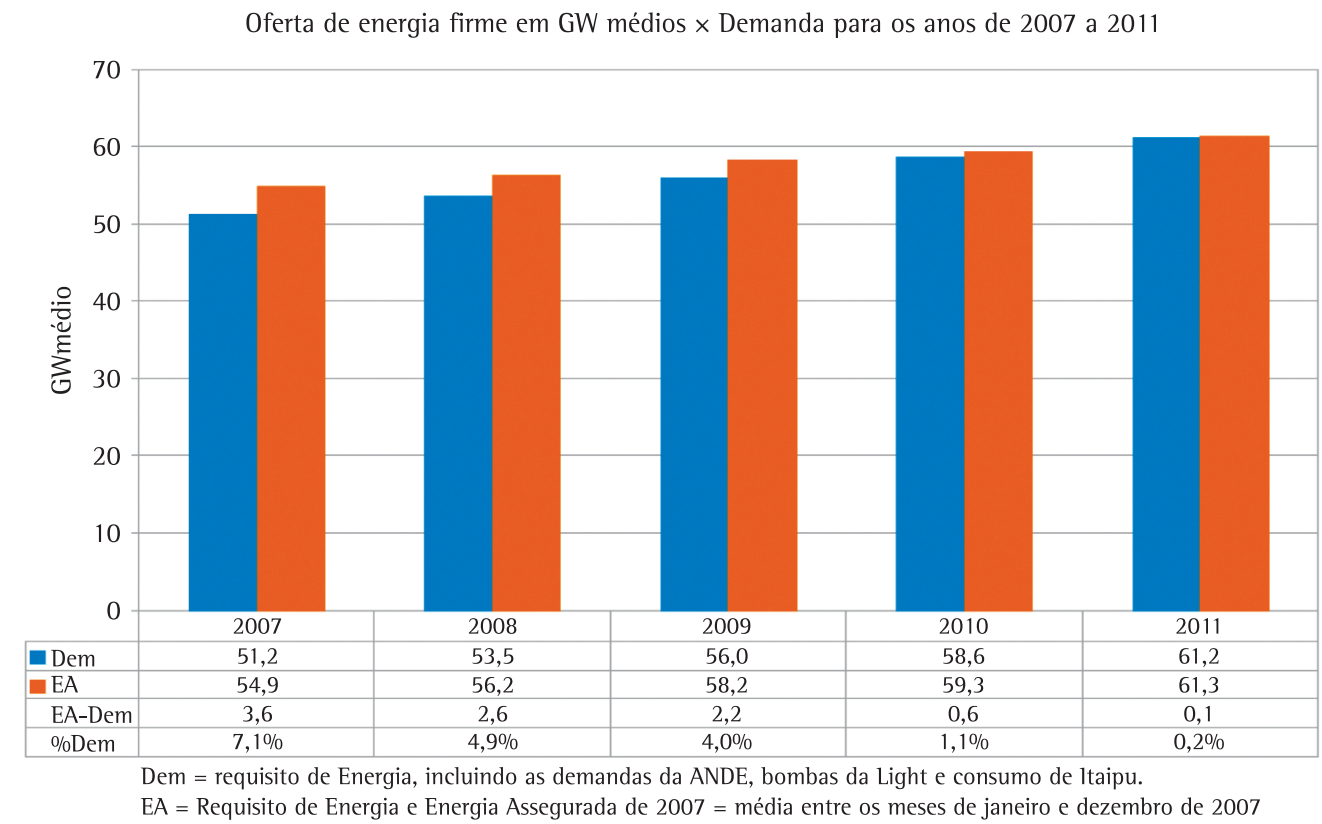

Figura 2. Balanço entre oferta de energia firme e demanda. Fonte: http://www.cni.org.br/portal/data/files/8A9015D015A0F71 F0115AE4B9A37466D/Matriz\%20Energ\%C3\%A9tica.pdf. 
Tabela 2. Consumo final energético por fonte.

\begin{tabular}{cccccccccc}
\hline \multirow{2}{*}{ Discriminação } & \multicolumn{2}{c}{2010} & \multicolumn{2}{c}{2014} & \multicolumn{2}{c}{2019} & \multicolumn{3}{c}{ Variação anual \% } \\
\cline { 2 - 9 } & 1.000 tep & $\%$ & 1.000 tep & $\%$ & 1.000 tep & $\%$ & $2010-14$ & $2015-19$ & $2010-19$ \\
\hline Gás natural & 16.560 & 7,3 & 27.174 & 9,4 & 32.239 & 8,8 & 17,1 & 3,5 & 10,1 \\
Carvão mineral e coque & 10.116 & 4,4 & 16.370 & 5,7 & 22.886 & 6,3 & 13,6 & 6,9 & 10,2 \\
Lenha & 18.053 & 7,9 & 19.741 & 6,8 & 24.424 & 6,7 & 2,7 & 4,3 & 3,5 \\
Carvão vegetal & 5.668 & 2,5 & 7.839 & 2,7 & 9.566 & 2,6 & 8,0 & 4,1 & 6,0 \\
Bagaço de cana & 33.217 & 14,6 & 41.647 & 14,4 & 53.466 & 14,6 & 7,1 & 5,1 & 6,1 \\
Eletricidade & 39.146 & 17,2 & 48.312 & 16,7 & 61.230 & 16,7 & 5,8 & 4,9 & 5,3 \\
Etanol & 14.928 & 6,5 & 20.032 & 6,9 & 26.839 & 7,3 & 11,6 & 6,0 & 8,8 \\
Biodiesel & 2.125 & 0,9 & 2.675 & 0,9 & 3.540 & 1,0 & 14,0 & 5,8 & 9,8 \\
Outros & 6.904 & 3,0 & 10.357 & 3,6 & 15.022 & 4,1 & 11,0 & 7,7 & 9,3 \\
Derivados de petróleo & $\mathbf{8 1 . 2 9 2}$ & 35,7 & 95.068 & 32,9 & 116.470 & 31,8 & 4,4 & 4,1 & 4,3 \\
Óleo diesel & 38.251 & 16,8 & 48.645 & 16,8 & 64.939 & 17,8 & 6,0 & 5,9 & 6,0 \\
Óleo combustível & 5.824 & 2,6 & 7.555 & 2,6 & 9.054 & 2,5 & 6,5 & 3,7 & 5,1 \\
Gasolina & 15.034 & 6,6 & 12.531 & 4,3 & 11.944 & 3,3 & $-2,8$ & $-1,0$ & $-1,9$ \\
Gás liquefeito & 7.976 & 3,5 & 8.900 & 3,1 & 10.029 & 2,7 & 2,9 & 2,4 & 2,6 \\
Querosene & 2.867 & 1,3 & 3.548 & 1,2 & 4.554 & 1,2 & 5,7 & 5,1 & 5,4 \\
Outros derivados & 11.340 & 5,0 & 13.889 & 4,8 & 1.950 & 4,4 & 6,9 & 2,8 & 4,8 \\
Cons. final energético & 228.009 & 100,0 & 289.216 & 100,0 & 365.682 & 100,0 & 7,1 & 4,8 & 5,9 \\
\hline
\end{tabular}

Fonte: http://www.epe.gov.br/PDEE/20101129_1.pdf.

do consumo elétrico mundial e com um programa de plantio de 100 milhões de hectares de culturas voltadas para essa finalidade seria possivel atender $30 \%$ do consumo. Vista como uma das mais viáveis na geração de energia elétrica no Brasil, a biomassa possui muitas vantagens socioeconômicas. Ela é fonte nativa e renovável, dois importantes aspectos para a preservação do meio ambiente, inclusive contribui para a redução de queimadas em canaviais. 0 aproveitamento da biomassa para a geração de eletricidade no país ainda é tímido. Em meados de 2007, o Brasil possuía 271 empreendimentos com mais de 3,4 mil MW instalados. Com o bagaço de cana-de-açúcar, eram 225 unidades de geração, equivalentes a 2,3 mil MW (AGÊNCIA..., 2011). Seu uso ocorre, principalmente, em sistemas de cogeração e no suprimento de eletricidade para demandas isoladas da rede elétrica. Porém, a médio e longo prazo, a matéria-prima tende a apresentar outras utilidades energéticas, devido à expectativa de exaustão de fontes não renováveis (MONTÓIA, 2009; AMBIENTE..., 2010). A Tabela 4 apresenta a situação de empreendimentos termelétricos no Brasil, classificados por fonte e situação.

0 aproveitamento da matéria-prima para a geração de biomassa pode ser feito diretamente por meio de:

- Combustão direta, com ou sem processos físicos de secagem, classificação, compressão, corte/quebra e outros;

- Processos termoquímicos, como gaseificação, pirólise, liquefação e transesterificação; ou

- Processos biológicos, como digestão anaeróbia e fermentação.
Tabela 3. Capacidade instalada em 31/12/2009.

\begin{tabular}{lcc}
\hline \multicolumn{1}{c}{ Fonte } & MW & Participação \% \\
\hline Hidráulica (a) & 74.279 & 71,7 \\
Térmica & 13.302 & 12,8 \\
Nuclear & 2.007 & 1,9 \\
Fontes alternativas & 7.645 & 7,4 \\
Potência instalada & 97.233 & 93,9 \\
Importação contratada (b) & 6.365 & 6,1 \\
Potência total com importação & 103.598 & 100,0 \\
\hline
\end{tabular}

(a) Inclui a parte brasileira da UHE Itaipu (7.000 MW), (b) Importação da UHE Itaipu não consumida pelo sistema paraguaio. Fonte: ONS. Fonte: http://www. epe.gov.br/PDEE/20101129_1.pdf.

Tabela 4. Empreendimentos termelétricos no Brasil com uso de biomassa no ano de 2009.

\begin{tabular}{cccc}
\hline Combustivel & $\begin{array}{c}\text { Potência } \\
\text { (MW) }\end{array}$ & Combustivel & $\begin{array}{c}\text { Potência } \\
\text { (MW) }\end{array}$ \\
\hline $\begin{array}{c}\text { Lixo urbano e } \\
\text { gás natural } \\
\text { Bagaço de cana }\end{array}$ & $\begin{array}{c}600,00 \\
\text { Oleo diesel e } \\
\text { biomassa }\end{array}$ & 70,20 \\
$\begin{array}{c}\text { Licor negro } \\
\text { Licor negro e } \\
\text { biomassa } \\
\text { Biomassa }\end{array}$ & $\begin{array}{c}\text { Lixo urbano } \\
\text { Biomassa e óleo } \\
\text { combustivel }\end{array}$ & 26,30 \\
& 82,75 & $\begin{array}{c}\text { Lenha picada } \\
\text { Biomassa e bagaço } \\
\text { de cana }\end{array}$ & $5,80,31$ \\
& Total & 4,00 & $1.641,59$ \\
\hline
\end{tabular}

Fonte: http://ambientes.ambientebrasil.com.br/energia/biomassa/biomassa_e_ eletricidade.html.

\subsection{Matérias-primas}

Praticamente todos os organismos biológicos que podem ser aproveitados como fontes de energia são chamados de biomassa. Entre as matérias-primas mais utilizadas estão: cana-de-açúcar e derivados como o 
bagaço e a palha da cana e o vinhoto; lixo urbano e esgoto; e resíduos agroindustriais, como casca de toras, cavacos de madeira, casca de babaçu, casca de arroz, sabugo, palha de milho e outros. A palha de arroz, por exemplo, é geradora de biogás que pode substituir o gás de cozinha (VALOR..., 2008). No Brasil, a lenha ocupa a terceira posição como fonte de energia utilizada, sendo extraída das poucas reservas que restam no país. 0 bagaço e a palha da cana são matérias-primas de destaque como fontes energéticas nesse novo processo. Uma tonelada de cana contém energia equivalente a 1,2 barris de petróleo, sendo que cerca de 1/3 dessa energia está armazenada quimicamente no caldo (açúcares) e o restante na biomassa da cana: metade no bagaço e metade na palha, aproximadamente (GOES, 2008). 0 desenvolvimento da cogeração de energia a partir da biomassa, impulsionada pelo Programa de Incentivo às Fontes Alternativas de Energia Elétrica - Proinfa, colocou o setor sucroalcooleiro em novo patamar de importância. Afirma-se que em pouco tempo as usinas não serão mais somente indústrias de açúcar e álcool mas biorrefinarias. 0 bagaço de cana tem um grande potencial como fonte renovável de energia, podendo ser utilizado não somente em caldeiras para geração de calor e eletricidade no processo industrial de fabricação de álcool e açúcar, mas também na geração de excedentes de energia elétrica que podem ser comercializados. 0 aproveitamento da palha como recurso energético surge também como alternativa (VALOR..., 2008). A capacidade instalada no Brasil para produção de eletricidade a partir da biomassa da cana-de-açúcar, em 2011, era de 7.000 MW, em mais de 340 usinas (EMPRESA..., 2001). Em sua totalidade, as usinas termoelétricas (com e sem o uso da biomassa) respondem por $26,6 \%$ do parque energético brasileiro, com oferta de 31.011 megawatts (EMPRESA..., 2001). A maioria das termoelétricas (57\% do total) ainda é movida exclusivamente a óleo diesel. Essa percentagem dá a dimensão da potencialidade de inclusão das formas mais limpas de energia, tanto que as térmicas alimentadas por bagaço de cana já ocupam o segundo lugar em número e em oferta de energia. Existe o perigo de as emissões de gás carbônico das termelétricas subirem $172 \%$, passando de 14,43 milhões de toneladas para 39,3 milhões de toneladas. Existe ainda a previsão de criação de 71 hidrelétricas. 0 potencial hidrelétrico a ser instalado será bem maior que o do novo parque termelétrico, com 28.938,5 MW. A Tabela 5 mostra a quantidade de cana destinada a açúcar e etanol.

A biomassa possui muitas vantagens socioeconômicas e possivelmente é uma das fontes de geração de energia elétrica mais viáveis no Brasil. Ela é fonte nativa e renovável, dois importantes aspectos
Tabela 5. Cana destinada ao açúcar e ao etanol no Brasil.

\begin{tabular}{ccc}
\hline \multicolumn{3}{c}{ Cana destinada a açúcar e etanol } \\
\hline & Cana para açúcar (Mt) & Cana para etanol (Mt) \\
\hline $2006 / 2007$ & 187,35 & 226,11 \\
$2007 / 2008$ & 192,52 & 242,88 \\
$2008 / 2009$ & 205,84 & 296,32 \\
$2009 / 2010$ & 231,29 & 311,55 \\
$2010 / 2011$ & 250,94 & 309,76 \\
\hline
\end{tabular}

Fonte: CONAB [6]. Fonte: EPE.

para a preservação do meio ambiente, inclusive contribui para a redução de queimadas em canaviais. Em colheitas mecanizadas, as pontas e a palha da cana não precisam ser queimadas e podem ser usadas para a produção de energia elétrica. Em São Paulo, onde a lei $n$. 11.241 de setembro de 2002 determina a eliminação da prática de queima em canaviais, o índice de mecanização é de 45\%. No centro-sul do país, a média é de $36 \%$. 0 uso da biomassa pode colaborar para a redução de gases do efeito estufa, causadores do aquecimento global, e o uso de matéria orgânica tem caráter de desenvolvimento sustentável. 0 aproveitamento da biomassa para a geração de eletricidade no país ainda é tímido. Em 2007, o Brasil possuía 271 empreendimentos com mais de 3,4 mil MW instalados. Com o bagaço de cana-de-açúcar eram 225 unidades de geração, equivalentes a 2,3 mil MW. Seu uso ocorre, principalmente, em sistemas de cogeração e no suprimento de eletricidade para demandas isoladas da rede elétrica. Porém, a médio e longo prazo, a matéria-prima tende a apresentar outras utilidades energéticas, devido à expectativa de exaustão de fontes não renováveis. Do ponto de vista financeiro, a cogeração de bagaço de cana é um clássico de ganha-ganha para a indústria do açúcar, pois apresenta inúmeras vantagens em relação às fontes de geração de energia elétrica tradicionais. A cogeração de energia elétrica a partir do bagaço é atraente uma vez que combina baixo custo, eficiência e benefícios sociais a uma energia limpa; o processo de produção dessa fonte de energia não polui o ambiente essa energia é renovável. A cogeração do bagaço de cana-de-açúcar, especialmente o processo de geração de energia feito em alta temperatura e pressão, poderia desempenhar um papel importante no sentido de incentivar o uso mais eficiente dos recursos e aumentar o acesso da população ao serviço de eletricidade. Até recentemente, cerca de dois terços do bagaço de cana-de-açúcar colhida eram desperdiçados, esta situação tem melhorado com a elevação da tarifa da compra de energia de biomassa em países como o Brasil e a Índia. Os benefícios e as vantagens da cogeração de bagaço são:

- Aumento da viabilidade das fábricas de açúcar; 
- Custo de combustível praticamente nulo, pago em moeda local e que valoriza o resíduo do bagaço como um produto;

- Aumento da eficiência do combustível;

- Aumento da diversidade e segurança no fornecimento de eletricidade;

- Mais emprego para as populações locais;

- Maior disponibilidade de energia elétrica; e

- Fornecimento de energia "mais seguro e de confiança" para os consumidores já existentes.

\section{Apoio multicritério à decisão (AMD)}

0 AMD permite a priorização de alternativas em uma situação de critérios conflitantes, buscando satisfazer as restrições com objetivos conflitantes (BUCHANAN; GARDINER, 2003), ou seja, uma solução de compromisso. Assim sendo, o AMD pode fornecer mecanismos para o apoio à negociação e/ou decisão em grupo. Salienta-se que o AMD começa a busca da(s) alternativa(s) de solução do problema pela(s) alternativa(s) não dominada(s) (MARMOL; PUERTO; FERNÁNDEZ, 2002), ou seja, alternativa(s) que supera(m) outra(s) alternativa(s) em todos os critérios, evidenciando a hierarquia de preferência da(s) alternativa(s). Matsatsinis e Samaras (2001) afirmam que os métodos do AMD são uma excelente ferramenta para redução dos conflitos interpessoais quando o objetivo é obter o consenso, uma vez que buscam a minimização de conflitos individuais

No modelo para tomada de decisão estão compreendidos os seguintes componentes: critérios, pesos e as classificações que são dadas para cada alternativa, em cada critério. Pressupondo o conhecimento das preferências dos atores da decisão e a qualidade da avaliação, pode-se admitir que uma ação seja tão boa, melhor ou pior que outra, ou seja, hierarquizar as alternativas. Um grande obstáculo a qualquer processo de decisão em grupo e mais ainda na negociação é que cada participante tem a sua percepção do problema alterada de acordo com os resultados possíveis da decisão ou negociação. A percepção das diferenças de visões do problema e/ou preferências individuais aparece quando se pretende criar um modelo que agregue as preferências do grupo, baseado nas preferências individuais (BISHOP; STOCK. WILLIAMS, 2008). De acordo com o AMD, o critério é um eixo de comparação das alternativas e é expresso de forma qualitativa ou quantitativa, considerando os pontos de vista, objetivos, aptidões ou entraves relativos ao contexto real, permitindo o julgamento das ações potenciais. A família de critérios deve considerar todos os atores envolvidos no processo decisório, ou seja: decisores, agentes, facilitadores e analistas (GOMES; GOMES, 2012), para continuar o apoio à decisão, e deve conter um número suficientemente "pequeno" de critérios que permita, em uma análise intercritério, obter informação necessária para implementar um processo “de agregação" (GOMES; GOMES, 2012). No contexto do AMD, o resultado pretendido em determinado problema pode ser identificado entre quatro tipos de problemática de referência, descritos a seguir:

- Problemática P. $\alpha$ - Tem como objetivo esclarecer a decisão pela escolha de um subconjunto tão restrito quanto possível, tendo em vista a escolha final de uma única ação. Esse conjunto conterá as "melhores ações" ou as ações "satisfatórias". 0 resultado pretendido é, portanto, uma escolha ou um procedimento de seleção;

- Problemática P. $\beta$ - Tem como objetivo esclarecer a decisão por uma triagem resultante da alocação de cada ação a uma categoria (ou classe). As diferentes categorias são definidas a priori com base em normas aplicáveis ao conjunto de ações. 0 resultado pretendido é, portanto, uma triagem ou um procedimento de classificação;

- Problemática P. $\gamma$ - Tem como objetivo esclarecer a decisão por um arranjo obtido pelo reagrupamento de todas ou parte (as mais satisfatórias) das ações em classes de equivalência. Essas classes são ordenadas de modo completo ou parcial, conforme a preferência. 0 resultado pretendido é, portanto, um arranjo ou um procedimento de ordenação; e

- Problemática P. $\delta$ - Tem como objetivo esclarecer a decisão por uma descrição, em linguagem apropriada, das ações e de suas consequências. 0 resultado pretendido é, portanto, uma descrição ou um procedimento cognitivo.

Deve-se ressaltar que as problemáticas definidas anteriormente não são independentes umas das outras. Em particular, a ordenação das alternativas (P. $\gamma$ ) pode servir de base para resolver um problema P. $\alpha$ ou P. $\beta$. Na prática, muitos métodos multicritério, sobretudo aqueles desenvolvidos nos anos 70 e princípio dos anos 80, privilegiaram a problemática P. $\gamma$. 0 caso em estudo neste trabalho é o P. $\gamma$. Os modelos baseados em decisão multicritério são indicados para problemas onde existam vários critérios de avaliação (ZAMBON et al., 2005).

$\mathrm{Na}$ análise multicritério são considerados diversos pontos de vista para avaliar o desempenho de cada alternativa com relação a cada um dos objetivos estabelecidos. De um modo geral, para que o objetivo final possa ser alcançado, é preciso que um fator relevante para a diferenciação das alternativas seja considerado, o que muitas vezes pode elevar o número de critérios a serem utilizados. Deve-se destacar que o valor do resultado final é sempre dependente dos 
critérios considerados e da metodologia escolhida, que, por sua vez, são sempre função do agente de decisão (AD), tornando a análise subjetiva (CHAVES et al., 2010).

Os métodos da escola francesa utilizam a noção de relação de superação, possuindo duas vertentes principais: os métodos ELECTRE e os métodos PROMÉTHÉE. A mais conhecida família de métodos de subordinação é a família ELECTRE. Esses métodos têm origem no trabalho de Roy em 1968, sendo adotados tanto no apoio quanto na tomada de decisão. A família ELECTRE é composta, atualmente, pelos seguintes métodos: ELECTRE 1 e 1S, ELECTRE 11, ELECTRE 111, ELECTRE IV e ELECTRE TRI (COSTA et al., 2007). Os métodos multicritério da escola americana, por sua vez, têm como fundamentação teórica a noção de agregar todas as informações acerca do problema que se pretende resolver por meio de uma grande síntese. Exemplos significativos desses métodos são a teoria de utilidade multiatributo e os métodos de análise hierárquica; dentre esses, o mais popular é, indiscutivelmente, o método AHP (RANGEL; GOMES, 2010). A escolha de um método específico dependerá de vários fatores, como as características do problema, do contexto considerado, da estrutura de preferências do decisor e da problemática (VALOIS; ALMEIDA, 2009)

\subsection{Sistema de apoio à decisão (SAD) THOR}

0 SAD THOR é baseado em três algoritmos que devem ser usados simultaneamente: teoria da utilidade, modelagem de preferência e teoria de multiatributo. 0 uso dessas teorias permite que a atratividade de uma alternativa seja quantificada pela criação de uma função agregação não transitiva. 0 uso do termo SAD deve-se ao fato de o software que implementou o THOR apresentar um banco de modelos, pois possui três algoritmos para ordenação, bem como usar o Rough Set (teoria dos conjuntos aproximativos) como data mining, possuir um banco de dados, denominado Firebird, e uma interface de comunicação construída na linguagem Delphi7.

As descrições do algoritmo THOR e do software que lhe dá suporte e aplicações estão em: Alencar, Gomes e Costa (2005), Gomes (2005), Gomes et al. (2009), Lira, Mota e Gomes (2006), Cardoso et al. (2009), Gomes, Gomes e Rangel (2009) e Gomes e Trevisan (2010). As referências Cardoso et al. (2009), Gomes, Xavier e Valle (2008), Gomes, Gomes e Maranhão (2010) são aplicações do THOR em situações de reciclagem e/ou energia, o que sugere uma aplicação da metodologia no problema deste artigo. A metodologia usada no THOR utiliza, em sua formulação, a modelagem de preferências e não obriga a transitividade - esses conceitos foram apresentados ao decisor, que considerou conveniente o seu uso.

\subsection{Técnica de destilação}

A técnica de destilação ordena a informação de duas diferentes formas:

- Uma ordenação descendente é obtida por um algoritmo que primeiro seleciona a melhor opção e elimina essa opção do processo decisório; posteriormente refaz o processo de decisão, eliminando a que se apresenta como melhor, até chegar à pior opção; e

- Uma ordenação ascendente é obtida por um algoritmo que primeiro seleciona a pior opção e elimina essa opção do processo decisório; posteriormente refaz o processo de decisão, eliminando a que se apresenta como pior, e finaliza com a melhor opção.

\section{Estudo de caso}

Os estudos que seguem têm como objetivo auxiliar uma empresa no processo de tomada de decisão de qual tipo de biomassa deverá ser utilizada para gerar energia. Será utilizado o SAD THOR. Foram selecionados cinco tipos de biomassa produzidos no Brasil e possíveis de serem utilizadas pela empresa que financiou o estudo:

a) Licor negro ou lixívia negra: é um fluído processual produzido à saída do digestor, responsável pela cozedura da madeira, para retirar componentes indesejáveis como lenhina, extrativos e cinzas do processo de fabricação do papel. A polpação é o processo pelo qual a madeira é reduzida a uma massa fibrosa. Isto significa romper as ligações entre as estruturas da madeira, separando as fibras. Para cada tonelada de polpa produzida tem-se de 9 a 15 mil litros de licor negro. Por razões econômicas e ambientais, o licor negro precisa ser recuperado;

b) Bagaço de cana-de-açúcar: é um dos subprodutos da indústria da cana, assim como a sacarose e a palha. É constituído por celulose, hemicelulose e lignina. Atualmente, o bagaço gerado na usina é consumido na produção de energia por meio da cogeração, tornando a usina autossustentável energeticamente e, em alguns casos, superavitária - sobra energia para venda de eletricidade. 0 bagaço pode servir também como matéria-prima na produção de etanol (a Figura 3 apresenta a produção mundial de etanol) por meio da hidrólise ácida ou enzimática, nas quais as frações celulose e hemicelulose são convertidas a hexoses e pentoses. Após processos de purificação, a mistura obtida pode ser fermentada para produção do etanol. O Plano Decenal de Expansão de Energia (PDE) 2019 já salienta que a biomassa de cana-de-açúcar para geração de energia elétrica está em plena análise. A biomassa de cana-de-açúcar é consumida principalmente na produção de açúcar e etanol no Brasil. De acordo 


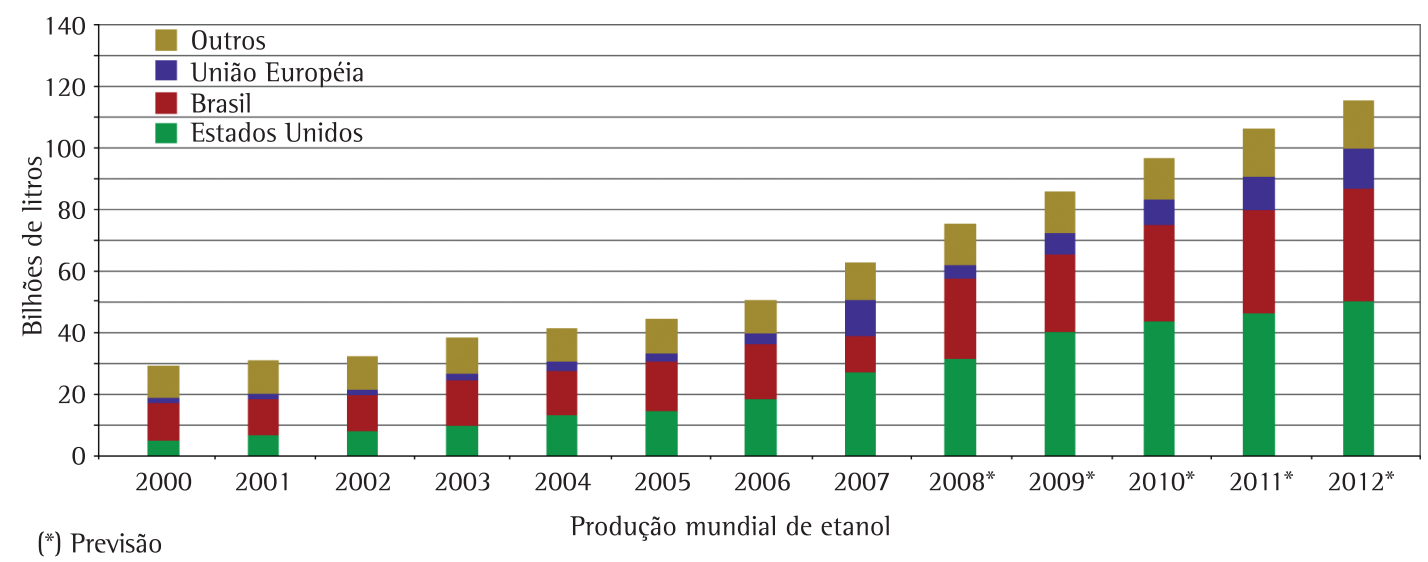

Fonte: Unica (2008)

Figura 3. Produção mundial de etanol. Fonte: http://www.aneel.gov.br/arquivos/PDF/atlas_par2_cap4.pdf

com dados do Balanço Energético Nacional, em 2008 cerca de 54\% das 134,7 milhões de toneladas de bagaço consumidas para fins energéticos foram destinados à produção de açúcar. A produção de etanol, por sua vez, absorveu os $46 \%$ restantes (http://www.epe.gov.br/PDEE/20101129_1.pdf);

c) Biogás: é um tipo de mistura gasosa produzida naturalmente, de forma anaeróbica, pela ação de bactérias em matéria orgânica fermentada sob temperatura, teor de umidade e acidez controladas. A composição do biogás é difícil de ser definida, pois depende do material orgânico a partir do qual foi gerado e do tipo de tratamento anaeróbio que sofreu. Contudo, em linhas gerais, o biogás é uma mistura gasosa composta principalmente por: metano $\left(\mathrm{CH}_{4}\right): 50 \%$ a $70 \%$ do volume de gás produzido; dióxido de carbono (gás carbônico, $\mathrm{CO}_{2}$ ): 25\% a $50 \%$ do volume de gás produzido; e traços de outros gases - hidrogênio $\left(\mathrm{H}_{2}\right)$ : 0 a 1\% do volume; gás sulfídrico $\left(\mathrm{H}_{2} \mathrm{~S}\right): 0$ a $3 \%$ do volume; oxigênio $\left(\mathrm{O}_{2}\right): 0$ a $2 \%$ do volume; amoníaco $\left(\mathrm{NH}_{3}\right): 0$ a $1 \%$ do volume; e nitrogênio $\left(\mathrm{N}_{2}\right)$ : 0 a $7 \%$ do volume;

d) Resíduos de madeira: sobras de qualquer tipo de madeira. Estima-se que, no Brasil, a indústria de celulose e papel gere, aproximadamente, 5 MTOE de resíduos sem aproveitamento energético; e

e) Casca de arroz: o arroz colhido é transportado com casca para a usina. Ao longo de um ano, aproximadamente $15 \%$ da casca produzida são destinados à secagem do arroz, atividade que ocorre principalmente no período de colheita (janeiro a abril). A secagem se concentra nesses meses, consumindo $60 \%$ da casca recolhida. Estima-se que, de toda a casca produzida ao longo de um ano, apenas 50\% possam ser utilizados na produção de eletricidade, uma vez que, além dos 15\% destinados à secagem, cerca de 35\% são disponibilizados em pequenas indústrias, espacialmente dispersas. A casca é um material de densidade muito baixa, sendo o transporte viabilizado apenas como frete de retorno. 0 poder calorífico superior, em base seca, da casca de arroz, é de 15,84 GJ/t. 0 poder calorífico inferior, com umidade de $11 \%$, é de $12,96 \mathrm{GJ} / \mathrm{t}$, muito superior ao bagaço de cana.

0 estudo identificou quatro critérios que permitem a comparação entre as alternativas. Esses critérios forma escolhidos pela operacionalidade, podem ser usados pelo AMD e é possível classificar todas as alternativas neles; pela não redundância, não existe um aspecto presente em dois ou mais critérios; e pela exaustividade, quando duas alternativas classificam-se com a mesma pontuação em todos os critérios, as duas possuem a mesma atratividade. Face ao anteriormente exposto, não foi possivel identificar mais critérios a serem utilizados no estudo.

1)Número de usinas: número total de usinas em operação do Brasil em 2011, segundo a Agência Nacional de Energia (ANEEL);

2)Potência: total de megawatts produzidos no Brasil, em 2011, segundo a ANEEL;

3) R\$/MW: o valor da energia contratada em leilão, em reais por megawatts/hora; e

4) Produção: produção média por usina, corresponde ao total de MW produzidos com cada tipo de biomassa divididos pelo número total de usinas de cada tipo de biomassa.

A Tabela 6 apresenta os tipos de biomassa estudados e a classificação em cada critério.

A Tabela 7 apresenta, na primeira coluna, os critérios e, na segunda, o peso atribuído a cada um. Esses pesos representam a importância de cada critério e foram obtidos pelo uso de entrevistas com os decisores e a utilização do módulo do SAD THOR para elicitação de pesos junto a estes decisores. 
0 valor da energia vendida em reais por megawatts/hora (R\$/MW) foi considerado o critério de maior importância e recebeu peso igual a 4. É vantajoso para os consumidores finais se a energia produzida for vendida a preço acessível. Busca-se assim resolver o problema da escassez de energia com preço acessível. 0 segundo critério de maior peso nessa avaliação foi a potência, com peso 3 - na visão dos decisores deve-se levar em consideração o tipo de biomassa mais produzido em nosso país. 0 terceiro critério de maior peso foi a produção, com peso 2. Na visão dos decisores, em relação a esse critério, média de MW que cada usina em produção hoje, no Brasil, gera, não adianta ter muitas usinas de um determinado tipo de biomassa se cada usina produz uma quantidade insignificante de energia. 0 critério de menor peso neste estudo foi o critério número de usinas, que ficou com peso 1.

Observação: o valor de $P$ foi escolhido como aproximadamente $1 \%$ do valor da melhor alternativa classificada no critério, e o valor de Q foi arbitrado como metade do valor de P (Tabela 8). Para uma alternativa (alternativa a) ter preferência forte $(\mathrm{aPb}) \mathrm{em}$ relação a outra (alternativa b), o valor da classificação da alternativa a no critério i $(g(a) i)$ tem de ser superior ao valor $\mathrm{p}$.

$\mathrm{aPb}=(\mathrm{g}(\mathrm{a}) \mathrm{i})-(\mathrm{g}(\mathrm{b}) \mathrm{i})>\mathrm{p}$; preferência forte.

$\mathrm{aQb}=\mathrm{q}<(\mathrm{g}(\mathrm{a}) \mathrm{i})-(\mathrm{g}(\mathrm{b}) \mathrm{i}) \leq \mathrm{p} ;$ preferência fraca.

$\mathrm{alb}=(\mathrm{g}(\mathrm{a}) \mathrm{i})-(\mathrm{g}(\mathrm{b}) \mathrm{i}) \leq \mathrm{q} ;$ indiferença.

Tabela 6. Alternativas e critérios utilizados no estudo

\begin{tabular}{ccccc}
\hline $\begin{array}{c}\text { Alternativas/ } \\
\text { critérios }\end{array}$ & Usinas & Potência (MW) & R\$/MW & Produção \\
\hline Licor negro & 14 & 1.245 & 117 & 88,9 \\
Bagaço de cana & 344 & 7.155 & 156 & 20,8 \\
$\quad$ Biogás & 15 & 70 & 85 & 4,6 \\
$\begin{array}{c}\text { Resíduo de } \\
\text { madeira }\end{array}$ & 42 & 373 & 160 & 8,8 \\
$\begin{array}{c}\text { Casca de arroz } \\
\text { (1) }\end{array}$ & 8 & 32 & 102 & 4,0 \\
\hline
\end{tabular}

Tabela 7. Peso dos critérios.

\begin{tabular}{cc}
\hline Critérios utilizados & Peso atribuído ao critério \\
\hline Número de usinas & 1 \\
Produção & 2 \\
Potência & 3 \\
R\$/MW & 4 \\
\hline
\end{tabular}

Tabela 8. Limiares de preferência dos critérios.

\begin{tabular}{ccc}
\hline Critérios utilizados & Valor $\mathrm{p}$ & Valor $\mathrm{q}$ \\
\hline Número de usinas & 3,44 & 1,72 \\
Produção & 0,89 & 0,45 \\
Potência & 7,15 & 3,60 \\
$\mathrm{R} \$ / \mathrm{MW}$ & 1,60 & 0,80 \\
\hline
\end{tabular}

Para maiores esclarecimentos sobre limiares de preferência, consultar Gomes e Gomes (2012).

A aplicação dos dados apresentados nas Tabelas 6, 7 e 8 no SAD THOR gerou as ordenações relacionadas na Tabela 9.

A alternativa bagaço de cana foi a alternativa escolhida.

\subsection{Análise de sensibilidade}

Para licor negro: a alteração do peso do critério produção de 2 para 8 ou superior acarretará uma preferência pela alternativa licor negro (Tabela 10).

Para resíduo de madeira: passa a alternativa preferida se mudar o peso do critério $\mathrm{R} \$ / \mathrm{MW}$ de 4 para 7 ou superior (Tabela 11).

Dessa forma verifica-se que bagaço de cana sempre fica entre as duas alternativas mais preferidas. Verifica-se que aplicando-se o módulo de data mining que utiliza a teoria dos conjuntos aproximativos (TCA) do SAD THOR - utilizado para eliminar critérios "irrelevantes" em estudos anteriormente feitos (GOMES; GOMES, 2012), o critério número de usinas pode ser retirado sem que haja alteração da ordenação, logo esse critério é considerado irrelevante.

\subsubsection{Destilação - teoria dos conjuntos aproximativos (TCA)}

Foi feita uma análise de sensibilidade utilizando-se o conceito de destilação descendente e eliminando-se a alternativa casca de arroz, que ficou em última colocação em todas as ordenações (Tabelas 9, 10 e 11). Foi retirado o critério número de usinas, considerado irrelevante pela análise com uso da TCA (SIKDER; MUNAKATA, 2009). Posteriormente foi alterado o peso do critério produção de 2 para 5 , valor intermediário entre 2 e 8 , e alterado o peso do critério $\mathrm{R} \$ / \mathrm{MW}$ de 4 para 5,5, valor intermediário entre 4 e 7 (Tabela 12). As alterações de peso foram acordadas com os decisores.

0 resultado é apresentado na Tabela 13. Essa análise sugeriu/confirmou a preferência por bagaço de cana, ficando licor negro como segunda opção, resíduo de madeira como terceira e biogás como quarta.

Tabela 9. Ordenação das alternativas.

\begin{tabular}{cccc}
\hline Alternativa & Ordenação S1 & Ordenação S2 & Ordenação S3 \\
\hline Bagaço de cana & 3,2 & 3,2 & 3,2 \\
Licor negro & 2,5 & 2,5 & 2,5 \\
$\quad \begin{array}{l}\text { Resíduo de } \\
\text { madeira }\end{array}$ & 2,3 & 2,3 & 2,29 \\
$\quad$ Biogás & 0,5 & 0,5 & 0,6 \\
Casca de arroz & 0,5 & 0,5 & 0 \\
\hline
\end{tabular}


Tabela 10. Análise de sensibilidade para licor negro.

\begin{tabular}{cccc}
\hline Alternativa & Ordenação S1 & Ordenação S2 & Ordenação S3 \\
\hline Licor negro & 3,19 & 3,19 & 3,19 \\
Bagaço de cana & 2,75 & 2,75 & 2,75 \\
Biogás & 1,5 & 1,69 & 1,75 \\
Resíduo de & 1,5 & 1,5 & 1,5 \\
madeira & 0,5 & 0 & 0 \\
Casca de arroz & & &
\end{tabular}

Tabela 11. Análise de sensibilidade para resíduo de madeira.

\begin{tabular}{cccc}
\hline Alternativa & Ordenação S1 & Ordenação S2 & Ordenação S3 \\
\hline $\begin{array}{c}\text { Resíduo de } \\
\text { madeira }\end{array}$ & 3 & 3 & 3 \\
$\begin{array}{c}\text { Bagaço de cana } \\
\text { Licor negro }\end{array}$ & 2,69 & 2,69 & 2,69 \\
Biogás & 2 & 2 & 2 \\
Casca de arroz & 0,54 & 0,54 & 0,62 \\
& 0 & 0 & 0 \\
\hline
\end{tabular}

Tabela 12. Análise de sensibilidade dos pesos.

\begin{tabular}{cc}
\hline Critérios utilizados & Peso atribuido ao critério \\
\hline Produção & 5 \\
Potência & 1 \\
$\mathrm{R} \$ / \mathrm{MW}$ & 5,5 \\
\hline
\end{tabular}

Tabela 13. Ordenação das alternativas com a análise de sensibilidade dos pesos.

\begin{tabular}{cccc}
\hline Alternativa & Ordenação S1 & Ordenação S2 & Ordenação S3 \\
\hline $\begin{array}{c}\text { Bagaço de } \\
\text { cana }\end{array}$ & 1,65 & 1,65 & 1,65 \\
$\begin{array}{c}\text { Licor negro } \\
\text { Resíduo de }\end{array}$ & 1,52 & 1,52 & 1,52 \\
madeira & 0,57 & 0,57 & 0,57 \\
Biogás & 0 & 0 & 0 \\
\hline
\end{tabular}

\section{Conclusão e considerações finais}

A crise financeira que o mundo vem enfrentando, iniciada em 2008, com contínuos reflexos ainda em 2012, acarretou uma diminuição na projeção de crescimento do nosso país, causando uma diminuição no crescimento da demanda por energia. 0 Brasil teve uma variação negativa no crescimento do PIB no ano de 2009 , valor de $-0,6 \%$, colocando o país tecnicamente em recessão, mas teve um crescimento de 7,5\% em 2010; em 2011 o crescimento do PIB é pouco superior a 3\%. É preciso que o país invista no setor de geração de energia elétrica, de forma eficiente, que possa auxiliar a redução dos custos (menor preço da energia), com menos impacto no meio ambiente, diversificando sua matriz energética, e principalmente que incentivando a geração de energia a partir de fontes limpas e renováveis.

A cogeração de energia elétrica a partir do bagaço mostra-se atraente, uma vez que combina baixo custo, eficiência e benefícios sociais com uma energia limpa, cujo processo de produção que não polui o ambiente, e é renovável. Hoje, o Brasil é um dos principais produtores de etanol do mundo, combustível oriundo da cana-de-açúcar. Como o bagaço da cana-de-açúcar não é aproveitado no processo produtivo do etanol nem no do açúcar, outra indústria de importância no Brasil, a cogeração desse bagaço, especialmente o processo de geração de energia feito em alta temperatura e pressão, pode desempenhar um papel importante no incentivo ao uso mais eficiente dos recursos e no aumento do acesso da população ao serviço de eletricidade. Neste estudo, a biomassa bagaço de cana foi a que mais se destacou. Ressalta-se que apesar de considerar essa biomassa uma excelente fonte de energia para o Brasil, não se pode defender a ideia de investirmos em apenas uma única fonte de energia. A solução para a possível falta na oferta de energia está no investimento em um conjunto de fontes de energia limpa e renovável.

\section{Referências}

AGÊNCIA NACIONAL DE ENERGIA ELÉTRICA - ANEEL. Disponível em: <www.aneel.gov.br>. Acesso em: 2011.

ALENCAR, L. H.; GOMES, C. F. S.; COSTA, A. P. C. S. Gerenciamento de projeto na construção civil - estudo de caso utilizando o Sistema de Apoio à Decisão (SAD) THOR. Pesquisa Naval, v. 18, p. 110-117, 2005.

ALVES, J. 0. Eco-eficiência na produção de energia com biomassa de mamona: além do biodiesel. 2007. Dissertação (Mestrado em Engenharia de Regulação da indústria de energia)-Universidade de Salvador, Salvador, 2007. p. 77-98.

AMBIENTE BRASIL. 2010. Disponível em: <http://www. ambientebrasil.com.br/composer.php3?base=./energia/ index.html\&tconteudo=./energia/artigos/petroleo_vida. html>.

BIOWARE. Disponível em: <http://www.bioware.com.br>. Acesso em: 2009.

BISHOP, 1. D.; STOCK, C.; WILLIAMS, K. J. Using virtual environments and agent models in multi-criteria decision-making. Land Use Policy, v. 26, p. 87-94, 2008. http://dx.doi.org/10.1016/j.landusepol.2008.01.010

BUCHANAN, J.; GARDINER, L. A comparation of two reference point methods in multiple objective mathematical programming. European Journal of Operational Research, v. 149, n. 1, p. 17-43, 2003. http://dx.doi.org/10.1016/ S0377-2217(02)00487-3

CARDOSO, R. et al. Uso de SAD no Apoio à Decisão na Destinação de Resíduos Plásticos e Gestão de Materiais. Pesquisa Operacional, v. 29, n. 1, p. 67-95, jan./abr. 2009. http://dx.doi.org/10.1590/S0101-74382009000100004

CARMO, B. B. T.; BARROS NETO, J. F.; DUTRA, N. G. S. Análise do impacto nos custos de transporte de um modelo de seleção de fornecedores baseado em variáveis socioambientais e de competitividade. Produção, v. 21, n. 3, p. 466-483, 2011. http://dx.doi.org/10.1590/ S0103-65132011005000013

CHAVES, M. C. C. et al. Utilização do método ELECTRE 11 para avaliação de pilotos no campeonato de Fórmula 1. 
Produção, v. 20, n. 1, p. 102-113, 2010. http://dx.doi. org/10.1590/S0103-65132010005000012

COSTA, F. G. et al. A ELECTRE TRl aplicado a avaliação da satisfação de consumidores. Produção, v. 17, n. 2, p. 230-245, 2007. http://dx.doi.org/10.1590/ S0103-65132007000200002.

EMPRESA DE PESQUISA ENERGÉTICA - EPE. Disponível em: $<$ http://www.epe.gov.br/Paginas/default.aspx>. Acesso em: 2011.

GASPAR, M. Choque de pragmatismo - Um plano de recuperação leva a complicada light do prejuizo ao lucro, a guinada mais radical de todo o setor elétrico em 2007. Revista Exame, ed. 0915, p. 48-49, abr. 2008.

GOES, T. A energia que vem da cana-de-açúcar. Brasília: EMBRAPA, 2008. Disponivel em: <http://www.embrapa. br/imprensa/artigos/2008/A\%20energia\%20que\%20 vem\%20da\%20cana\%20de\%20acucar\%20ultimo.pdf>. Acesso em: 2009.

GOMES, C. F. S. Using MCDA Methods THOR in an Application for Outranking the Ballast Water Management Options. Revista Pesquisa Operacional, v. 25, n. 1, p. 11-28, 2005. http://dx.doi.org/10.1590/S0101-74382005000100002

GOMES, C. F. S.; GOMES, L. F. A. M.; MARANHÃO, F. J. C. Decision Analysis for the Exploration of Gas Reserves: Merging TODIM AND THOR. Pesquisa Operacional, v. 30, n. 3, p. 601-617, jan./fev. 2010. http://dx.doi. org/10.1590/S0101-74382010000300006

GOMES, C. F. S. et al. Identificação de Hub Ports na Costa Brasileira Comparação Entre a Análise Conjunta e o Sad-Thor. Revista de la Escuela de Perfeccionamiento en Investigación Operativa, v. 17, p. 143-159, 2009.

GOMES, C. F. S.; TREVISAN , N. Metodologia Integrada para tomada de decisão com uso do apoio multicritério e análise de envoltória de dados (DEA). Revista de la Escuela de Perfeccionamiento en Investigación Operativa, v. 31, p. 57-76, 2010.

GOMES, C. F. S.; XAVIER, L. H.; VALLE, R. Multicriteria Decision Making Applied to Waste Recycling in Brazil. Omega - International Journal of Management of Science, v. 36, n. 3, p. 395-404, 2008. http://dx.doi. org/10.1016/j.omega.2006.07.009

GOMES, L. F. A. M.; GOMES, C. F. S.; RANGEL, L. A. D. A comparative Decision Analysis with THOR and TODIM: rental evaluation in Volta Redonda. Revista Tecnologia (UNIFOR), v. 30, p. 7-11, 2009.

GOMES, L. F. A. M.; GOMES, C. F. S. Tomada de Decisão Gerencial o Enfoque Multicritério. 4. ed. São Paulo: Atlas, 2012.
LIRA, C. F. A.; MOTA, C. M. M.; GOMES, C. F. S. Seleção de Contratos de Serviço na Construção Civil. SPOLM-2006, p. 187-194, 2006.

MAIA, A. C. C. Proposta de Uso da Biomassa de Bagaço de Cana de Açúcar como solução para a escassez no fornecimento de energia no Brasil. 2008. Trabalho de Conclusão de Curso (Graduação em Administração)-Faculdades IBMEC, Rio de Janeiro, 2008.

MARMOL, A. M.; PUERTO, J; FERNÁNDEZ, F. R. Sequential incorporation of imprecise information in multiple criteria decision processes. European Journal of Operational Research, v. 137, n. 1, p. 123-133, 2002. http://dx.doi. org/10.1016/S0377-2217(01)00082-0

MATSATSINIS, N. F.; SAMARAS, A. P. MCDA and preferences disaggregation in group decision support systems. European Journal of Operational Research, v. 130, n. 2, p. 414-429, 2001. http://dx.doi.org/10.1016/S03772217(00)00038-2

MONTÓı, P. Brasil: Energia múltipla. Planeta Sustentável. 2009. Disponível em: <http:// planetasustentavel.abril.com.br/noticia/energia/ conteudo_394752.shtml>.

RANGEL, L. A. D.; GOMES, L. F. A. M. 0 Apoio Multicritério à Decisão na avaliação de candidatos. Produção, v. 20 , n. 1, p. 92-101, 2010. http://dx.doi.org/10.1590/S010365132010005000016

SIKDER, 1. U.; MUNAKATA, T. Application of rough set and decision tree for characterization of premonitory factors of low seismic activity. Expert Systems with Applications, v. 36, n. 1, p. 102-110, 2009. http://dx.doi.org/10.1016/j. eswa.2007.09.032

VALOIS, Ú.; ALMEIDA, A. T. Modelo de apoio à decisão multicritério para terceirização de atividades produtivas baseado no método SMARTS. Produção, v. 19, n. 2, p. 249-260, 2009. http://dx.doi.org/10.1590/S010365132009000200003

VALOR ECONÔMICO. Análise Setorial. Disponível em: <http:// www.valoronline.com.br/>. Acesso em: 2008.

WIKIPÉDIA. Disponível em: <http://pt.wikipedia.org/wiki/ P\%C3\%A1gina_principal>. Acesso em: 2011.

WORLD WILDLIFE FUND - WWF. Natureza Brasileira. Disponivel em: <http://www.wwf.org.br/natureza_ brasileira/meio_ambiente_brasil/clima/mudancas_ climaticas_resultados/asust/rec/lielaoes/>. 2009.

ZAMBON, K. L. et al. Análise de decisão multicritério na localização de usinas termoelétricas utilizando SIG. Pesquisa. Operacional, v. 25, n. 2, p. 183-199, 2005. http://dx.doi.org/10.1590/S0101-74382005000200002

\section{Using multicriteria decision support in a biomass alternatives ordination problem}

\section{Abstract}

This work presents a study on a source of clean and renewable energy known as biomass. The production of electricity from biomass is much defended as an important alternative for many developing countries. The aim of this study was to show the potential of this source of energy - biomass, as a clean and safe alternative to address the possible rationing that Brazil may face in the coming years because of the disparity between energy demand growth and power supply growth in the country.

\section{Keywords}

Biomass. Energy. Multicriteria. 